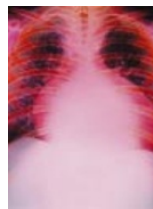

\section{Ghost writers}

The mystery of the paper the authors hadn't heard about p775

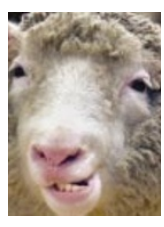

Goodbye, Dolly

Lung disease gets the better of the first cloned mammal p776

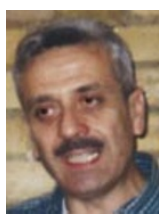

In the money

Donation boosts

Israeli-Palestinian collaboration p777

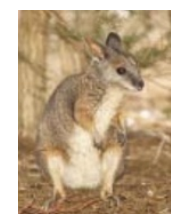

Jump to it

US institute urged to sequence wallaby genome

\title{
Error reports threaten to unravel databases of of mitochondrial DNA
}

Carina Dennis

More than half of all published studies of human mitochondrial DNA (mtDNA) sequences contain mistakes, according to a geneticist at the University of Cambridge.

To the occasional chagrin of his peers, Peter Forster has repeatedly pointed out errors in published mtDNA sequences, the genetic material from cells' mitochondria, which are inherited from the mother. But his commentary in the latest issue of Annals of Human Genetics ${ }^{1}$ argues that the problem is far bigger than researchers had imagined.

The mistakes may be so extensive that geneticists could be drawing incorrect conclusions in studies of human populations and evolution, says Forster. They may also confuse forensic analyses that rely on the published sequences, he adds.

"I was surprised by the number of errors," says Eric Shoubridge, a geneticist at McGill University's Montreal Neurological Institute in Canada, who investigates human diseases that result from problems with mtDNA. "What concerns me most is that these errors could be compounded in the databases."

Published mtDNA sequences are popular tools for investigating the evolution and

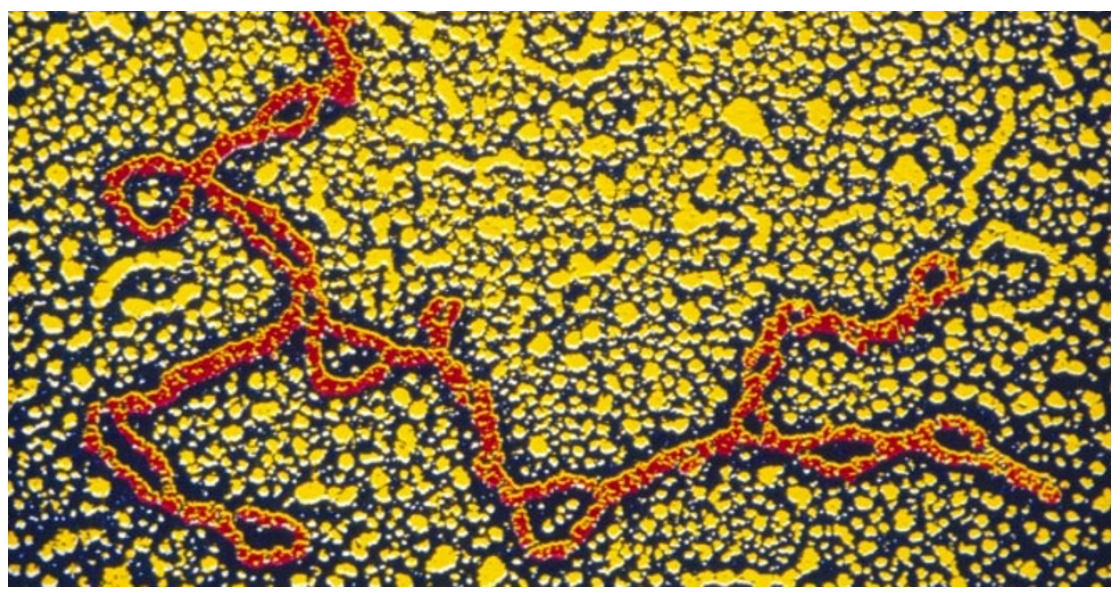

Human-population studies could be derailed by mistakes in recorded sequences of mitochondrial DNA

demography of human populations. Forster has been compiling a database of corrected mitochondrial sequences published since 1981, when the complete sequence of human mtDNA — known as the 'Cambridge reference sequence' - was published ${ }^{2}$. His colleagues' responses when he informs them of errors are varied. "Antagonism would be an understatement in some cases," he says. But he adds that authors are often forthcoming in resolving discrepancies in sequences.

Neil Howell, vice-president for research at MitoKor, a San Diego-based biotech company that specializes in mitochondrial disease, says that Forster's error-detection method, which involves constructing evolutionary trees based on how sequences change, may even underestimate the extent

\section{Nobel laureate slams misconduct smear}

\section{Quirin Schiermeier, Munich}

It's like a murder without a body. An alleged case of scientific misconduct has hit the headlines in Germany and Switzerland, even though no published scientific paper has been implicated.

On 11 February, the German daily newspaper Süddeutsche Zeitung reported allegations of bad scientific practice brought by a postdoc who used to work in the lab of 1996 Nobel prizewinner Rolf Zinkernagel.

"The damage to our reputation is huge," says Zinkernagel, who is director of the University of Zurich's Institute of Experimental Immunology.

The allegations of the former postdoc, a 35-year-old German medical scientist, centre on a manuscript submitted to Science last February. She claims that data in the paper were manipulated and that the article listed her as a co-author without her consent. The paper, a study of a cancer vaccine in mice, was withdrawn within hours of her protest.

Although Zinkernagel was not a co-author on the manuscript, the mice experiments were carried out in his lab. The study was led by Martin Bachmann, chief scientific officer of the Zurich-based vaccine company Cytos Biotechnology. Zinkernagel is a member of Cytos' scientific advisory board and has long been Bachmann's scientific mentor.

But bad blood has developed between Zinkernagel and his former postdoc, who claims that Zinkernagel was wrong not to halt the alleged manipulation of data in the study. "There was no publication and therefore no damage to science," says Zinkernagel, who feels unfairly smeared by the affair.

The university's attempts to resolve the postdoc's complaints failed. A subsequent independent investigation, however, reported that the submitted manuscript was misleading, concluding that Bachmann violated rules of good scientific practice. But Bachmann says that inadvertent errors were immediately corrected. The media response is a personal disaster for him, he says.

The postdoc was dissatisfied with the outcome and over the next few months she asked various newspapers and journals, including Nature, to publish the story. 
of the errors. Howell jointly led the team that resolved minor errors in the Cambridge reference sequence ${ }^{3}$.

The extent to which the field has been affected by mtDNA sequence errors is an open question. Forster's recent commentary was commissioned to accompany a controversial paper that re-appraises mtDNA data on European populations. The paper claims to refute earlier work that says Icelanders are less genetically heterogeneous than other European groups ${ }^{4}$.The extent to which erroneous sequence data affect the Icelandic issue is not resolved.

Known errors have led to a retraction of conclusions in at least one high-profile case. In 1999, a team led by scientists at the University of Cambridge seemed to have overturned dogma when they claimed to have shown mixing of maternal and paternal mtDNA by genetic recombination ${ }^{5}$. But their results were subsequently found to be based on mistakes in the sequence.

Some scientists question the impact that most of the sequence errors identified by Forster will have on published conclusions. "I would say that it is only a small number of cases where sequencing errors would affect the results," says Vincent Macaulay, a statistician at the University of Oxford.

Perhaps the gravest concern surrounds forensic investigations. Because large numbers of mitochondria are present in cells, they are often used to identify degraded samples from which nuclear DNA cannot be obtained. But the region of mtDNA typically used in forensics the 'control region' - is highly variable, says geneticist Douglas Wallace of the University of California, Irvine. "People don't appreciate the fact that the control region can undergo different mutations in different cells," he says. For instance, there might be differences between mtDNA from someone's blood and from the same person's hair follicle. "This erodes the reliability of forensic assays," he says.

Most errors in published mtDNA sequences are the result of poor documentation, Forster claims. "Mistakes occur between reading the sequencing output and publishing the results," he says. Journals are as much to blame as scientists, he adds, saying that editors should be more vigilant.

Forster notes that nuclear DNA sequences in public databases are also plagued by errors, and that this may be an even bigger problem, as such mistakes are more difficult to detect.

\footnotetext{
1. Forster, P. M. Ann. Hum. Genet. 67, 2-4 (2003).

2. Anderson, S. et al. Nature 290, 457-465 (1981).

. Andrews, R. M. et al. Nature Genet. 23, 147 (1999).

4. Abbott, A. Nature 421, 678 (2003).

Hagelberg, E. et al. Proc. R. Soc. Lond. B 266, 485-492

(1999); erratum, Proc. R. Soc. Lond. B 267, 1595 (2000).
}

\section{Researchers fear the future as Congress settles 2003 budget}

Hannah Hoag, Washington

Four-and-a-half months into the financial year, US research agencies finally know how much money they can spend this year.

The appropriations bill for 2003, which should have been agreed last October, was finally passed by both houses of Congress on 13 February. It provides large increases for the top two science agencies - the National Institutes of Health (NIH) and the National Science Foundation (NSF). But it has left some researchers worried that these agencies will see only slim increases in 2004.

Under the final 2003 budget, the NIH, which was set to complete a historic fiveyear doubling of its funding this year, will get $\$ 26.5$ billion. This is just shy of the $\$ 27.3$ billion that would have completed the doubling, and represents a $13 \%$ increase over the budget for 2002 . The NSF gets $\$ 5.3$ billion, an $11 \%$ increase over the 2002 budget.

The NSF increase was welcomed by some biomedical research organizations, which have recently been calling for Congress to treat the foundation as well as it traditionally treats the NIH. "For the biomedical sciences to flourish you need the contributions that the NSF makes," says Steven Teitelbaum, president of the Federation of American Societies for Experimental Biology.

But the confirmation of the figures for 2003 has put the budget proposed by President George Bush for 2004 (see Nature 421,

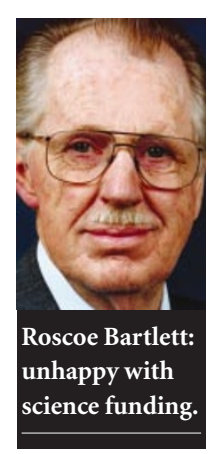

565 ; 2003) under fresh scrutiny. As things now stand, the president is proposing a $2 \%$ increase for the NIH next year and $3.4 \%$ for the NSF - even though the president signed a bill last December that recommended doubling the latter's funding over five years. "The level of funding proposed in the 2004 budget is far from adequate," says Congressman Roscoe Bartlett (Republican, Maryland), a member of the House Committee on Science.

There is little good news for physicists supported by the Department of Energy's Office of Science. The $\$ 3.3$ billion budget is a meagre $2 \%$ increase over last year. "It's a lousy situation," says April Burke of Washington lobbying firm Lewis-Burke Associates, but she remains hopeful that future budgets may be more generous.

The appropriations bill passed by the Congress also allowed NASA a \$500 million increase over last year — including an additional $\$ 50$ million for its investigation into the Columbia accident — bringing its total funding to $\$ 15.4$ billion.

President Bush is expected to sign the 2003 budget into law, leaving Congress free to busy itself with his 2004 proposal.

\section{Journals tighten up on biosecurity}

\section{Erika Check, Washington}

Last week's joint statement on the handling of sensitive biological information from a group of journal editors and authors (see page 771) has received a mixed response from researchers and security experts.

The statement, which was issued at the annual meeting of the American Association for the Advancement of Science in Denver, Colorado, says that the prospect of bioterrorism raises "legitimate concerns about the potential abuse of published information". It is a response to repeated calls from US government officials to address the issue (see Nature 421, 197; 2003), and commits the editors to modifying papers that they believe could represent a security threat.

Some researchers say that the statement does not take a strong enough stand in the defence of scientific freedom. "It is more equivocal and less definitive than I would like to see," says Steven Block, a biophysicist at Stanford University. But the journal editors insist that the peer-review process would not be compromised by new security concerns.

Ron Atlas, president of the American Society for Microbiology, says that in the past year the society has modified 2 out of 14,000 submitted papers for security reasons. In one, he says, an author had written that a toxin could kill 10,000 people, but that a molecular modification to it could kill a million people. The author was asked to delete the "cookbook detail" on the modified toxin. "I don't see this as censorship - I see it as an extension of the peer-review process," Atlas says.

Others say that scientists should go much further to address security concerns about life-sciences research. David Heyman, a science and security expert at the Center for Strategic and International Studies in Washington, says that the statement is "only a step" and that scientists should make changes earlier in the research process to reduce the risk of biological research being misused. 